\title{
Cocaine self-administration alters the relative effectiveness of multiple memory systems during extinction
}

\author{
Amanda Gabriele, Barry Setlow, and Mark G. Packard ${ }^{1}$ \\ Department of Psychology, Texas A\&M University, College Station, Texas 77843, USA
}

\begin{abstract}
Rats were trained to run a straight-alley maze for an oral cocaine or sucrose vehicle solution reward, followed by either response or latent extinction training procedures that engage neuroanatomically dissociable "habit" and "cognitive" memory systems, respectively. In the response extinction condition, rats performed a runway approach response to an empty fluid well. In the latent extinction condition, rats were placed at the empty fluid well without performing a runway approach response. Rats trained with the sucrose solution displayed normal extinction behavior in both conditions. In contrast, rats trained with the cocaine solution showed normal response extinction but impaired latent extinction. The selective impairment of latent extinction indicates that oral cocaine self-administration alters the relative effectiveness of multiple memory systems during subsequent extinction training.
\end{abstract}

Understanding the psychological and neural mechanisms underlying the acquisition and extinction of drug-seeking behavior has important implications for therapies targeting drug addiction. A better understanding of the neurobiology of extinction can potentially allow for the development of treatments to produce more effective and persistent extinction learning. Dissociable hippocampus-dependent "cognitive" and dorsal striatal-dependent "habit" memory systems are engaged during the initial acquisition of learned behavior (for reviews, see Packard and Knowlton 2002; White and McDonald 2002; Squire 2004). Interestingly, recent evidence indicates that multiple memory systems can also be engaged during the new learning that occurs during behavioral extinction (Gabriele and Packard 2006). For example, the behavior of a rat trained to traverse a straight-alley runway for a food reward can be extinguished using either habit/response or cognitive/ latent extinction training procedures. During response extinction, rats are allowed to perform the runway approach response to an empty food cup. In contrast, during latent extinction, rats are placed at the empty food cup without performing the runway approach response. Consistent with evidence indicating a selective role for the hippocampus in cognitive memory, neural inactivation of this brain structure impairs latent extinction and spares response extinction (Gabriele and Packard 2006). Moreover, consistent with evidence that the dorsal striatum selectively mediates habit memory (for review, see Packard and Knowlton 2002), neural inactivation of this brain region impairs response extinction and spares latent extinction (A. Gabriele and M.G. Packard, unpubl.).

The transition from initial drug use to eventual addiction may involve, at least in part, the development of compulsive drugseeking and drug-taking behaviors that are increasingly guided by dorsal striatal-dependent habit learning mechanisms (for reviews, see White 1996; Everitt et al. 2001; Everitt and Robbins 2005; Belin et al. 2008). This hypothesis raises the possibility that once "habitlike" drug-seeking behaviors are firmly acquired, the extinction of such behaviors may be differentially influenced by engaging habit and cognitive memory systems. In the present study, we examined

'Corresponding author.

E-mail mgp@psyc.tamu.edu; fax (979) 845-4727.

Article is online at http://www.learnmem.org/cgi/doi/10.1101/lm.1253409. this idea by comparing the relative effectiveness of response and latent extinction training procedures in rats trained to run a straight-alley maze for an oral cocaine reward. Consistent with criteria considered important for demonstrating drug dependence, oral cocaine self-administration produces withdrawal following forced abstinence (Barros and Miczek 1996) and additionally is resistant to reinforcer devaluation (Miles et al. 2003), indicating that this behavior becomes divorced from its consequences in a manner similar to the dorsal striatum-mediated compulsive drug-seeking behavior that may characterize addiction (for reviews, see White 1996; Everitt et al. 2001; Everitt and Robbins 2005; Belin et al. 2008).

The apparatus was an elevated $(86.4 \mathrm{~cm})$ straight-alley maze with a black Plexiglas floor and clear Plexiglas sides $(117.8 \mathrm{~cm}$ long, $11.4 \mathrm{~cm}$ wide, and $20.3 \mathrm{~cm}$ tall). A fluid cup $(2.5-\mathrm{cm}$ diameter) was located at the goal end of the maze. The maze was located in a room containing several extra-maze cues.

Subjects were 32 adult male Long-Evans rats (275-300 g). Rats were individually housed on a 12:12-h light-dark cycle, with lights on from 8:00 a.m.-8:00 p.m. All animals received food ad libitum.

During all behavioral procedures, water bottles were removed from home cages $24 \mathrm{~h}$ prior to training, and animals received 15 $\mathrm{min} /$ day access to water following each day's procedures. Training began with $3 \mathrm{~d}$ of habituation to the solution to be used during training (cocaine-sucrose $[0.1 \%$ cocaine $\mathrm{HCl} / 20 \%$ sucrose in $\mathrm{ddH}_{2} \mathrm{O}$ ] or sucrose [ $20 \%$ in $\mathrm{ddH}_{2} \mathrm{O}$ ] alone). Each habituation day involved presentations of $0.5 \mathrm{~mL}$ of the solution in a novel environment consisting of a half-white, half-black box $(41.9 \mathrm{~cm}$ long, $31.8 \mathrm{~cm}$ wide, 35.6 tall) with the fluid cup located in the center of the black side. The number of presentations increased with each habituation day $(1,2$, and 4$)$. Each individual presentation had a maximum time of $20 \mathrm{~min}$, and rats were removed when the solution was consumed. Volume consumed and amount of time to consume the solution were recorded for each rat. Each sucrose rat was matched to a cocaine rat to ensure that there were no differences between groups in terms of volume of solution consumed prior to training. For each matched pair, the volume consumed by the rat receiving the cocaine solution during each presentation was measured, and an identical amount was made available to the matched sucrose animal. If, during any given 
presentation, the cocaine animal did not consume any solution, then the matched sucrose animal received $20 \mathrm{~min}$ in the habituation environment with no solution present.

Behavioral procedures were similar to those of our previous study using food reward (Gabriele and Packard 2006). During maze training, animals received either the cocaine-sucrose solution or sucrose vehicle solution reward. On days 1-10 of solutionrewarded maze training (six trials per day), rats were placed in the start end and allowed to traverse the maze and drink the available reward solution $(0.5 \mathrm{~mL})$. Upon consuming the solution, rats were removed from the maze and placed in an opaque holding box adjacent to the maze for a 30-sec intertrial interval. On each trial, the latency (in seconds) to reach the fluid cup was recorded and used as the measure of task acquisition. If a rat failed to reach the fluid cup within $60 \mathrm{sec}$, it was removed for the intertrial interval and a latency of $60 \mathrm{sec}$ was recorded.

Twenty-four hours following the completion of training (i.e., day 11), rats were assigned to one of two extinction conditions; latent extinction ( $n=18,10$ cocaine and eight sucrose) or response extinction ( $n=14$, seven cocaine and seven sucrose). For both the latent and response conditions, extinction training was administered over $3 \mathrm{~d}$ (six trials per day, 30-sec intertrial interval) with no reward solution present. In the latent extinction condition, rats were placed facing the empty fluid cup in the goal end of the maze and were confined for $60 \mathrm{sec}$ by placement of a clear Plexiglas barrier $20 \mathrm{~cm}$ from the rear wall of the goal end of the maze. Following confinement, rats were removed from the maze and placed in the holding box for the 30-sec intertrial interval. In the response extinction condition, rats were placed into the start end of the maze as during training and allowed to run to an empty fluid cup at the goal end of the maze. Upon reaching the empty fluid cup and being allowed to discover its emptiness (or after $60 \mathrm{sec}$ if the rat did not reach the reward cup), rats were removed from the maze and placed in the holding box for the 30-sec intertrial interval. Latency to reach the fluid cup was recorded and used as the measure of extinction behavior. On day 3 of extinction, 90 min following the sixth daily extinction trial, all rats were given an additional four extinction "probe" trials in which they were placed in the start end of the maze and latency to reach the empty fluid cup was recorded. These four trials allowed for an assessment of the effectiveness of each extinction procedure.

Data from the runway acquisition sessions are presented in Figure 1. A two-way one-repeated-measure ANOVA (Group [cocaine vs. sucrose] $\times$ Session) comparing the latencies to reach the fluid cup during acquisition in rats that subsequently received latent extinction revealed a significant effect of Session $\left(F_{(9,16)}=\right.$ 61.03, $P<0.001)$, indicating that latency to reach the fluid cup during acquisition decreased across sessions. However, the absence of a main effect of Group $\left(F_{(1,16)}=1.94\right.$, n.s. $)$ or interaction between Group and Session $\left(F_{(9,16)}=0.53\right.$, n.s. $)$ indicates that rats trained to run for cocaine and sucrose acquired the task at similar rates (Fig. 1A). Similar results were observed in rats that subsequently received response extinction (Fig. 1B) in that there was a main effect of Session $\left(F_{(9,12)}=13.11, P<0.001\right)$ but no main effect $\left(F_{(1,12)}=0.44\right.$, n.s.) or interaction $\left(F_{(9,12)}=1.50\right.$, n.s. $)$ involving drug Group.

The effects of oral cocaine self-administration on latent and response extinction are shown in Figure 2. A two-way ANOVA (Group $\times$ Extinction condition) comparing mean runway latencies (collapsed across the four probe trials) for each group revealed a significant main effect of Extinction condition $\left(F_{(1,28)}=32.440\right.$, $P<0.001)$, indicating that the response extinction procedures produced greater extinction of the runway response, and a significant interaction effect between Extinction condition and Group $\left(F_{(1,28)}=4.813, P<0.05\right)$ but no effect of Group $\left(F_{(1,28)}=0.96\right.$, n.s.). Simple effects tests showed a significant effect of Group
A

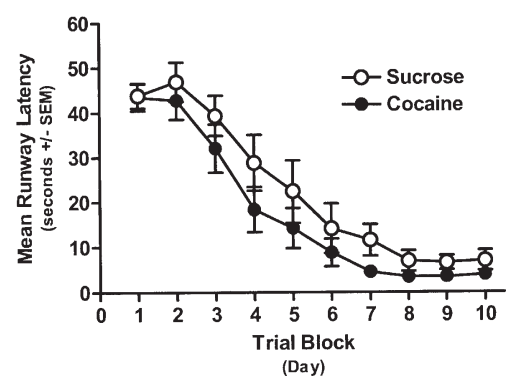

B

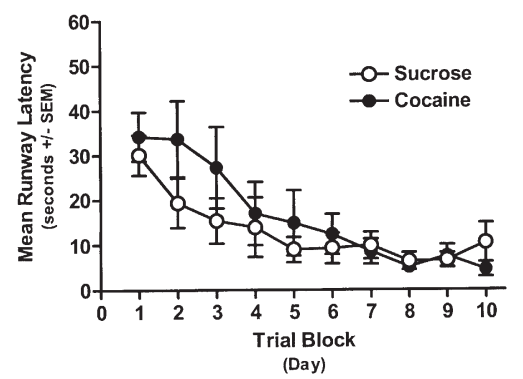

Figure 1. Acquisition of maze runway behavior. (A) Acquisition of maze runway behavior by rats that subsequently received latent extinction. $(B)$ Acquisition of maze runway behavior by rats that subsequently received response extinction. Mean \pm SEM of latency (in seconds) to reach the solution cup over training days. For both extinction conditions, there were no group differences in the initial acquisition of runway behavior.

within the latent extinction condition $\left(F_{(1,16)}=5.688, P<0.05\right)$ but not the response extinction condition $\left(F_{(1,12)}=0.663\right.$, n.s.), indicating that oral cocaine self-administration selectively impaired latent but not response extinction. Additionally, a twoway one-repeated-measure ANOVA (Group $\times$ Trial) computed on the latencies to reach the fluid cup during response extinction training revealed a main effect of Trial $\left(F_{(2,12)}=16.44, P<0.001\right)$, but no significant main effect $\left(F_{(1,12)}=2.27\right.$, n.s.) or interaction $\left(F_{(2,12)}=0.88\right.$, n.s. $)$ involving Group, further indicating that oral cocaine did not impair response extinction.

The present experiments investigated the effect of oral cocaine self-administration on response and latent extinction in a straight-alley maze. Following training, rats in the response extinction condition performed the approach response to an empty goal box, whereas rats in the latent extinction condition were placed in the goal box with no reward present. Consistent with previous studies using food reward (e.g., Seward and Levy 1949; Gabriele and Packard 2006), rats rewarded with a sucrose solution were able to extinguish the approach response following both response and latent extinction procedures. In contrast, rats rewarded with a cocaine solution displayed normal response extinction (see also Schoenbaum and Setlow 2005) but impaired latent extinction. The selective impairing effect of oral cocaine self-administration on latent extinction indicates that the drug does not impair processes that contribute to general maze behavior (e.g., motivational, motor, or sensory processes), as any such influence would also likely produce a deficit in response extinction.

Previous findings indicate that latent extinction of runway behavior is hippocampus dependent, whereas response extinction is dorsal striatal dependent (Gabriele and Packard 2006; A. Gabriele and M.G. Packard, unpubl.). In view of evidence that the hippocampus and dorsal striatum mediate cognitive and habit learning mechanisms, respectively (for reviews, see Packard and 


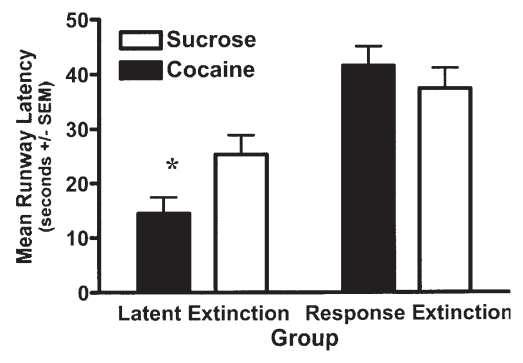

Figure 2. Effects of oral cocaine self-administration on extinction. The effect of oral cocaine self-administration on runway latent and response extinction. Mean \pm SEM latency (in seconds) to reach the fluid cup is shown over the four extinction probe trials. Oral cocaine selfadministration impaired latent extinction, but did not impair response extinction.

Knowlton 2002; White and McDonald 2002; Squire 2004), the findings suggest that oral cocaine self-administration can affect the relative use of multiple memory systems during extinction learning. The medial prefrontal cortex and basolateral amygdala have been implicated in extinction of several forms of learned behavior, and prior cocaine exposure can impair some forms of extinction learning (Burke et al. 2006; Peters et al. 2008; Quirk and Mueller 2008). However, neural inactivation of medial prefrontal cortex or basolateral amygdala does not affect latent extinction of maze runway behavior (A. Gabriele and M.G. Packard, unpubl.), suggesting that cocaine-induced dysfunction of these structures does not account for the results observed here.

One explanation of the cocaine-induced impairment of latent extinction is that the approach response acquired during task acquisition is guided by a supra-normal stimulus-response habit, thereby rendering cognitive learning mechanisms ineffectual during latent extinction training. Consistent with this possibility, drug-seeking behaviors underlying addiction may involve, at least in part, a transition from goal-directed behaviors to habitual behaviors that characterize the function of the dorsal striatal memory system (e.g., Tiffany 1990; White 1996; Packard 1999; Everitt et al. 2001; Porrino et al. 2004; Everitt and Robbins 2005; Belin et al. 2008). Indeed, recent evidence implicates the dorsal striatum in habitual drug-seeking behaviors. For example, intradorsal striatum administration of dopamine antagonists impairs cocaine seeking (Vanderschuren et al. 2005), and inactivation of the dorsal striatum attenuates drug seeking, following both abstinence and extinction (Fuchs et al. 2006; See et al. 2007). Interestingly, disconnection between the ventral and dorsolateral striatum impairs cocaine-seeking behavior (Belin and Everitt 2008), and extended cocaine use enhanced cueselective firing in the dorsal striatum and reduced cue-selective firing in the ventral striatum in go/no go discrimination learning, indicating an accelerated shift to dorsolateral striatal control (Takahashi et al. 2007). In addition, dopamine release increases in the dorsal striatum of rats following presentation of a responsecontingent cue associated with cocaine (Ito et al. 2002). Similar results from fMRI and PET studies of human cocaine addicts showed increased activation in the dorsal striatum (Garavan et al. 2000) and an increase in dopamine release within the dorsal striatum (Volkow et al. 2006) following cue-induced cravings.

A second explanation of the cocaine-induced impairment in latent extinction is that drug intake during task acquisition may have affected hippocampal physiology in a manner that negatively impacted the hippocampus-dependent learning that subsequently mediates latent extinction. Consistent with this possibility, chronic cocaine exposure impairs subsequent performance of hippocampus-dependent tasks such as the Morris water maze and the win-shift radial arm maze task (Melnick et al. 2001; Quirk et al. 2001; Mendez et al. 2008). However, it should be noted that the impairments observed in the latter studies were observed following exposure to cocaine doses considerably higher than those used in the present oral self-administration study. Since the current experiments do not explicitly examine the potential neurobiological progression underlying the acquisition of runway responding, further research is necessary to determine whether the cocaine-induced impairment of latent extinction involves the interfering effect of a supra-normal response habit, or a direct impairing effect on hippocampal physiology. It should also be noted that both oral cocaine self-administration and a passive cocaine administration regimen produce results analogous to those presented here, in that they impair "cognitive" representations of rewards (Miles et al. 2003; Schoenbaum and Setlow 2005). However, the relationship between this type of cognitive reward representation (mediated by interactions between basolateral amygdala and orbitofrontal cortex) (Pickens et al. 2003) and cognitive representations in latent extinction mediated by the hippocampus (Gabriele and Packard 2006) is currently unclear.

Finally, the selective impairing effect of cocaine selfadministration on latent extinction may have implications for understanding the persistent ability of drug-predictive cues and contexts to compel drug-seeking behavior and relapse. Specifically, if the ability to use cognitive learning mechanisms to extinguish drug-seeking behaviors is impaired following the transition from initial to habitual and compulsive drug use, then contextual/ relational cues might be expected to maintain greater control over behavior following extinction training. This in turn might suggest that incorporation of response extinction procedures into treatment strategies might provide greater therapeutic efficacy.

\section{Acknowledgments}

This research was supported by National Science Foundation Grant IBN-0312212 (M.G.P.) and National Institutes of Health Grant DA018764 (B.S.).

\section{References}

Barros, H.M.T. and Miczek, K.A. 1996. Withdrawal from oral cocaine in rats: Ultrasonic vocalizations and tactile startle. Psychopharmacology 125: 379-384.

Belin, D. and Everitt, B.J. 2008. Cocaine-seeking habits depend upon dopamine-dependent serial connectivity linking the ventral with the dorsal striatum. Neuron 57: 432-441.

Belin, D., Jonkman, S., Dickinson, A., Robbins, T.W., and Everitt, B.J. 2008 Parallel and interactive learning processes within the basal ganglia: Relevance for the understanding of addiction. Behav. Brain Res. 199: 89102 .

Burke, K.A., Franz, T.M., Gugsa, N., and Schoenbaum, G. 2006. Prior cocaine exposure disrupts extinction of fear conditioning. Learn. Mem. 13: 416421.

Everitt, B.J. and Robbins, T.W. 2005. Neural systems of reinforcement for drug addiction: From actions to habits to compulsion. Nat. Neurosci. 8: 1481-1489.

Everitt, B.J., Dickinson, A., and Robbins, T.W. 2001. The neuropsychological basis of addictive behavior. Brain Res. Brain Res. Rev. 36: 129-138.

Fuchs, R.A., Branham, R.K., and See, R.E. 2006. Different neural substrates mediate cocaine seeking after abstinence versus extinction training: A critical role for the dorsolateral caudate-putamen. J. Neurosci. 26: 35843588 .

Gabriele, A. and Packard, M.G. 2006. Evidence of a role for multiple memory systems in behavioral extinction. Neurobiol. Learn. Mem. 85: 289-299.

Garavan, H., Pankiewicz, J., Bloom, A., Cho, J., Sperry, L., Ross, T.J., Salmeron, B.J., Risinger, R., Kelley, D., and Stein, E.A. 2000. Cue-induced cocaine craving: Neuroanatomical specificity for drug users and drug stimuli. Am. J. Psychiatry 157: 1789-1798.

Ito, R., Dalley, J.W., Robbins, T.W., and Everitt, B.J. 2002. Dopamine release in the dorsal striatum during cocaine-seeking behavior under the control of a drug-associated cue. J. Neurosci. 22: 6247-6253. 
Melnick, S.M., Kubie, J.L., Laungani, R., and Dow-Edwards, D.L. 2001. Impairment of spatial learning following preweaning cocaine exposure in the adult rat. Neurotoxicol. Teratol. 23: 445-451.

Mendez, I.A., Montgomery, K.S., LaSarge, C.L., Simon, N.W., Bizon, J.L., and Setlow, B. 2008. Long-term effects of prior cocaine exposure on Morris water maze performance. Neurobiol. Learn. Mem. 89: 185191.

Miles, F.J., Everitt, B.J., and Dickinson, A. 2003. Oral cocaine seeking by rats: Action or habit? Behav. Neurosci. 117: 927-938.

Packard, M.G. 1999. Glutamate infused post-training into the hippocampus or caudate-putamen differentially strengthens place and response learning. Proc. Natl. Acad. Sci. 96: 12881-12886.

Packard, M.G. and Knowlton, B.J. 2002. Learning and memory functions of the basal ganglia. Annu. Rev. Neurosci. 25: 563-593.

Peters, J., LaLumiere, R.T., and Kalivas, P.W. 2008. Infralimbic prefrontal cortex is responsible for inhibiting cocaine seeking in extinguished rats. J. Neurosci. 28: 6046-6053.

Pickens, C.L., Saddoris, M.P., Setlow, B., Gallagher, M., Holland, P.C., and Schoenbaum, G. 2003. Different roles for orbitofrontal cortex and basolateral amygdala in a reinforcer devaluation task. J. Neurosci. 23: 11078-11084.

Porrino, L.J., Lyons, D., Smith, H.R., Daunals, J.B., and Nader, M.A. 2004. Cocaine self-administration produces a progressive involvement of limbic, association, and sensorimotor striatal domains. J. Neurosci. 24: 3554-3562.

Quirk, G.J. and Mueller, D. 2008. Neural mechanisms of extinction learning and retrieval. Neuropsychopharmacology 33: 56-72.

Quirk, P.J., Richards, R.W., and Avery, D.D. 2001. Subchronic cocaine produces training paradigm-dependent learning deficits in laboratory rats. Pharmacol. Biochem. Behav. 68: 545-553.
Schoenbaum, G. and Setlow, B. 2005. Cocaine makes actions insensitive to outcomes but not extinction: Implications for altered orbitofrontalamygdalar function. Cereb. Cortex 15: 1162-1169.

See, R.E., Elliott, J.C., and Feltenstein, M.W. 2007. The role of dorsal vs. ventral striatal pathways in cocaine-seeking behavior after prolonged abstinence in rats. Psychopharmacology 194: 321-331.

Seward, J.P. and Levy, N. 1949. Sign learning as a factor in extinction. J. Exp. Psychol. 39: 660-668.

Squire, L.R. 2004. Memory systems of the brain: A brief history and current perspective. Neurobiol. Learn. Mem. 82: 171-177.

Takahashi, Y., Roesch, M.R., Stanlaker, T.A., and Schoenbaum, G. 2007. Cocaine exposure shifts the balance of associative encoding from ventral to dorsolateral striatum. Front. Integr. Neurosci. 1: 11. doi: 10.3389/neuro.07.011.2007.

Tiffany, S.T. 1990. A cognitive model of drug urges and drug-use behavior: Role of automatic and nonautomatic processes. Psychol. Rev. 97: 147-168.

Vanderschuren, L.J.M.J., Di Ciano, P., and Everitt, B.J. 2005. Involvement of the dorsal striatum in cue-controlled cocaine seeking. J. Neurosci. 25: 8665-8670.

Volkow, N.D., Wang, G.J., Telang, F., Fowler, J.S., Logan, J., Childress, A.R., Jayne, M., Ma, Y., and Wong, C. 2006. Cocaine cues and dopamine in dorsal striatum: Mechanism of craving in cocaine addiction. J. Neurosci. 26: 6583-6588.

White, N.M. 1996. Addictive drugs as reinforcers: Multiple partial actions on memory systems. Addiction 91: 921-949.

White, N.M. and McDonald, R.J. 2002. Multiple parallel memory systems in the brain of the rat. Neurobiol. Learn. Mem. 77: 125-184.

Received October 8, 2008; accepted in revised form March 5, 2009. 


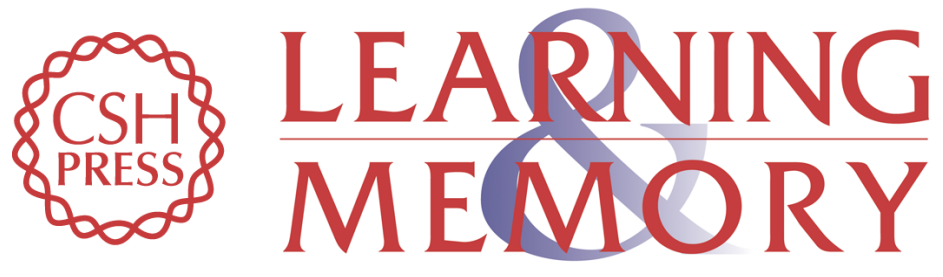

\section{Cocaine self-administration alters the relative effectiveness of multiple memory systems during extinction}

Amanda Gabriele, Barry Setlow and Mark G. Packard

Learn. Mem. 2009, 16:

Access the most recent version at doi:10.1101//m.1253409

References This article cites 30 articles, 9 of which can be accessed free at: http://learnmem.cshlp.org/content/16/5/296.full.html\#ref-list-1

License

Email Alerting Receive free email alerts when new articles cite this article - sign up in the box at the Service top right corner of the article or click here. 